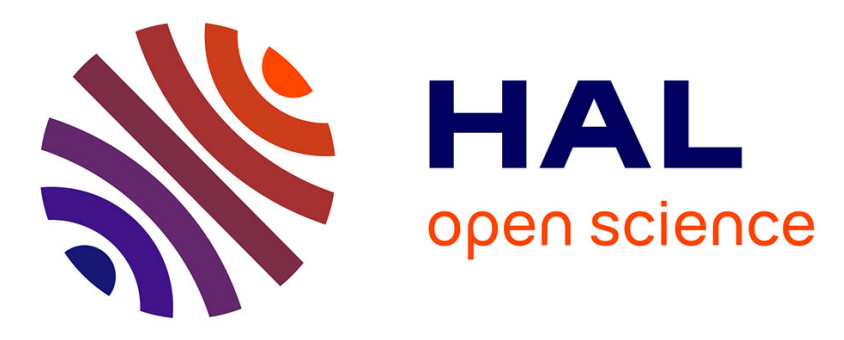

\title{
Heat flux measurement from thermal infrared imagery in low-flux fumarolic zones: Example of the Ty fault (La Soufrière de Guadeloupe)
}

Damien Gaudin, François Beauducel, Pascal Allemand, Christophe Delacourt, Anthony Finizola

\section{To cite this version:}

Damien Gaudin, François Beauducel, Pascal Allemand, Christophe Delacourt, Anthony Finizola. Heat flux measurement from thermal infrared imagery in low-flux fumarolic zones: Example of the Ty fault (La Soufrière de Guadeloupe). Journal of Volcanology and Geothermal Research, 2013, 267, pp.47-56. 10.1016/J.JVOLGEORES.2013.09.009 . insu-00933596

\section{HAL Id: insu-00933596 https://hal-insu.archives-ouvertes.fr/insu-00933596}

Submitted on 3 Nov 2016

HAL is a multi-disciplinary open access archive for the deposit and dissemination of scientific research documents, whether they are published or not. The documents may come from teaching and research institutions in France or abroad, or from public or private research centers.
L'archive ouverte pluridisciplinaire HAL, est destinée au dépôt et à la diffusion de documents scientifiques de niveau recherche, publiés ou non, émanant des établissements d'enseignement et de recherche français ou étrangers, des laboratoires publics ou privés. 


\title{
Heat flux measurement from thermal infrared imagery in low-flux fumarolic zones: Example of the Ty fault (La Soufrière de Guadeloupe)
}

\author{
Damien Gaudin $^{\mathrm{a}, *}$, François Beauducel ${ }^{\mathrm{b}}$, Pascal Allemand ${ }^{\mathrm{c}}$, Christophe Delacourt $^{\mathrm{a}}$, Anthony Finizola \\ d \\ a Laboratoire Domaines Océaniques, UMR 6538, Université de Bretagne Occidentale, IUEM, Place Nicolas Copernic, 29280 \\ Plouzané, France \\ b Institut de physique du globe de Paris, Sorbonne Paris Cité, Univ. Paris Diderot, UMR 7154 CNRS, France \\ C Université Lyon 1 et ENS de Lyon, CNRS, Laboratoire de Géologie de Lyon, UMR 5276, 2 rue Raphaël Dubois, 69622 \\ Villeurbanne Cedex, France \\ d Laboratoire GeoSciences Réunion, Université de La Réunion, Institut de Physique du Globe de Paris, Sorbonne Paris Cité, \\ UMR 7154 CNRS, France
}

\section{A B S T R A C T}

Monitoring the geothermal flux of a dormant volcano is necessary both for hazard assessment and for studying hydrothermal systems. Heat from a magma body located at depth is transported by steam to the surface, where it is expelled in fumaroles if the heat flow exceeds $500 \mathrm{~W} / \mathrm{m}^{2}$. If the heat flow is lower than $500 \mathrm{~W} / \mathrm{m}^{2}$, steam mainly condensates in the soil close to surface and produces a thermal anomaly detectable at the surface. In this study, we propose a method to quantify low heat fluxes from temperature anomalies measured at the surface by a thermal infrared camera. Once corrected from the atmospheric and surface effects, thermal infrared images are used to compute (1) the excess of radiative flux, (2) the excess of sensible flux and (3) the steam flux from the soil to the atmosphere. These calculations require measurements of atmospheric parameters (temperature, wind velocity and humidity) and estimations of surface parameters (roughness and emissivity). This method has been tested on a lowflux fumarolic zone of the Soufrière volcano (Guadeloupe Island - Lesser Antilles), and compared to a flux estimation realized from the thermal gradient measurements into the soil. The two methods show a good agreement and a similar precision $\left(267 \pm 46 \mathrm{~W} / \mathrm{m}^{2}\right.$ for the thermal infrared method, and $275 \pm 50 \mathrm{~W} / \mathrm{m}^{2}$ for the vertical temperature gradient method), if surface roughness is well calibrated.

\section{Introduction}

Heat and gas emission in fumarolic zones is one of the most obvious signals of the activity of dormant volcanoes (Noguchi and Kamiya, 1963; Baxter et al., 1999). Gas is mainly composed of water issued from the vaporization of meteoritic water (Aubert, 1999) in the hot environment surrounding the magmatic body or issued from the magmatic body itself. The gas also contains less than $20 \%$ of $\mathrm{CO}_{2}, \mathrm{CH}_{4}$, $\mathrm{SO}_{2}$ and other secondary species (Allard et al., 1998; Brombach et al., 2000). Gas flows upward from the magmatic environment through connected porosity and fissures of rocks in which the thermal vertical gradient is nil. Near the surface, the rock temperature decreases and steam condenses, either in the soil or in the atmosphere (Aubert, 1999). In the case of low heat flux fumarolic zones $\left(<500 \mathrm{~W} \cdot \mathrm{m}^{-2}\right)$, most of the condensation occurs into the soil where heat is transported both by conduction (Sekioka and Yuhara, 1974; Aubert, 1999) and advection (Sekioka and Yuhara, 1974). The excess heat flow transported in fumarolic zones, called geothermal flux in this paper, is at least three orders of magnitudes larger than the average heat flow of the Earth. It can reach $100 \mathrm{~W} \cdot \mathrm{m}^{-2}$ for the geothermal zones of dormant volcanoes

\footnotetext{
* Corresponding author at: INGV Roma, Via Di Vigna Murata, 605, 00143 Roma, Italy. Tel.: + 390651860638 .

E-mail address: damien.gaudin@ingv.it (D. Gaudin).
}

such as Satsuma Iwojima (Yuhara et al., 1978) and Unzen volcanoes (Japan) (Yuhara et al., 1981). At Fossa crater of Vulcano (Italy), the geothermal flux was estimated at $37 \mathrm{~W} \cdot \mathrm{m}^{-2}$ by Gaonac'h et al. (1994) and $43 \mathrm{~W} \cdot \mathrm{m}^{-2}$ by Harris and Stevenson (1997a). Harris and Stevenson (1997a) measured a heat flow of $111 \mathrm{~kW} \cdot \mathrm{m}^{-2}$ in a $2 \mathrm{~m}$ lava conduit of Stromboli (Italy), and a $36 \mathrm{~W} \cdot \mathrm{m}^{-2}$ in the surroundings.

The monitoring of fumarolic zones is essential for the study of hydrothermal systems (Sekioka and Yuhara, 1974), for the estimation of a global heat flux of the volcanic edifice, as well as for risk management (Pieri and Abrams, 2005). The heat flux can be retrieved classically by estimating the heat flow transported into the soil (Aubert, 1999; Aubert et al., 2008; Peltier et al., 2012) from temperature gradient and soil conductivity measurements. This method has been widely used for example at Mount Hood (Friedman et al., 1982), Mount Rainier (Frank, 1985), Etna (Aubert, 1999) or at Vulcano (Aubert et al., 2008). Measured fluxes are typically a few hundreds of watt per square meter. However, this method requires heavy infrastructures, including costly permanent stations. Furthermore, the flow is measured only at some points. This method does not provide a synoptic view of heat flow variations.

The geothermal flux can also be estimated via the measurement of surface temperature anomalies by thermal infrared cameras (Sekioka and Yuhara, 1974; Yuhara et al., 1978, 1981). Indeed, this temperature excess is related to an excess surface heat flux corresponding to the geothermal flux. The relationship between the temperature anomaly 
and the excess surface heat flux has been widely studied in the case of lava flows (Oppenheimer, 1993; Wright et al., 2001), where the excess of heat is mainly released through infrared radiation (Harris and Rowland, 2009). In that case, the relation between heat flow and thermal anomaly depends mainly on rock emissivity. For weaker heat flux anomalies, the proportion of the flux released through atmospheric convection becomes dominant. This component is more difficult to evaluate because it depends on numerous parameters related to meteorological and surface conditions. Fumarolic zones of Satsuma Iwojima (Yuhara et al., 1978) and Unzen volcanoes (Yuhara et al., 1981) using the Sekioka and Yuhara (1974) protocol. The surface parameters were not explicitly taken into account in these studies leading to uncertainties reaching up to $400 \%$ (Neri, 1998), and no specific model for the steam flux was offered. Moreover the repeatability of measurement was not demonstrated nor discussed, despite its crucial role in distinguishing the real evolution of the hydrothermal system from the measurement variability.

In order to improve, validate, and estimate the precision of heat flow measurement by infrared camera, a new protocol was built and applied to the data acquired on "Ty Fault", a low flux fumarolic zone of La Soufrière volcano in the Guadeloupe archipelago. In this paper, we detail the equations and the parameters that have to be taken into account in the heat flux estimation, and we validate the method by comparing the results with an estimation made by vertical thermal gradient measurement.

\section{Geodynamical context}

La Soufrière volcano $\left(16^{\circ} 02^{\prime} \mathrm{N}, 61^{\circ} 39^{\prime} \mathrm{S}, 1467 \mathrm{~m}\right.$ asl. $)$ is part of a volcanic complex located on Basse Terre Island in the Guadeloupe archipelago. Basse Terre is part of the Lesser Antilles volcanic arc (Fig. 1), approximately $300 \mathrm{~km}$ west from the westward subduction zone of the Atlantic crust under the Caribbean plate (Rodriguez, 1998; Feuillet et al., 2001, 2002). The island consists of a WNW/ESE volcanic chain, with decreasing ages southward. Northern volcanoes are $3.5 \mathrm{My}$ old whereas "Grande Découverte" complex, in the south of island is 200 ky old. "La Soufrière de Guadeloupe" lava dome is part of this youngest complex, and probably formed 1530 AD (Boudon et al., 2008).

The lava dome has a truncated cone shape with a diameter of $900 \mathrm{~m}$ at its base, $400 \mathrm{~m}$ at its top, and $300 \mathrm{~m}$ height. The dome is crossed by the Ty fault, a regional tectonic structure (Feuillet et al., 2002) whose direction is N140 (Fig. 2). Since the last magmatic eruption in 1530, at least six phreatic eruptions occurred (Feuillard et al., 1983; Komorowski et al., 2005). The last one took place in 1976-1977 and was widely studied (Pozzi et al., 1979; Le Guern et al., 1980; Sheridan, 1980; Feuillard et al., 1983). After this eruption, the hydrothermal and fumarolic activity decreased. Only the Ty Fault zone and the summit plateau kept a visible activity. The global activity of the dome increased again in 1992 with a background low-energy and shallow seismicity and significant fumarolic degassing at the summit. Since about ten years, the hydrothermal activity at the Ty fault is decreasing again (OVSG-IPGP, 2012).

The studied area intersects the Ty Fault on the southern border of the dome (Fig. 2). It is affected by hydrothermal alteration (Fig. 3 and Nicollin et al., 2006) and few cold $\left(<40^{\circ} \mathrm{C}\right)$ condensed water fumaroles are noticeable. The measurements of the temperature of the soil at a depth of $30 \mathrm{~cm}$ with a step of $1 \mathrm{~m}$ shows a well-localized $30 \mathrm{~m}$ wide thermally active zone (Finizola, personal communication). The occurrence of $\mathrm{CO}_{2}, \mathrm{CH}_{4}$ and $\mathrm{SO}_{2}$ in the soil, (Allard et al., 1998; Brombach et al., 2000) confirms the magmatic origin of the thermal anomaly.

\section{Temperature anomalies and heat flux}

The geothermal flux $\left(\varphi_{\mathrm{g}}-\right.$ see a list of symbols in Table 1) generates a positive temperature anomaly at the surface. This exceeding heat is dissipated by three distinct mechanisms: (1) radiation $\left(\varphi_{\mathrm{r}}\right)$, (2) atmospheric convection $\left(\varphi_{s}\right)$, and (3) release of residual steam into the atmosphere $\left(\varphi_{v}\right)$ (Sekioka and Yuhara, 1974; Harris and Stevenson, 1997b; Matsushima et al., 2003; Harris et al., 2009).

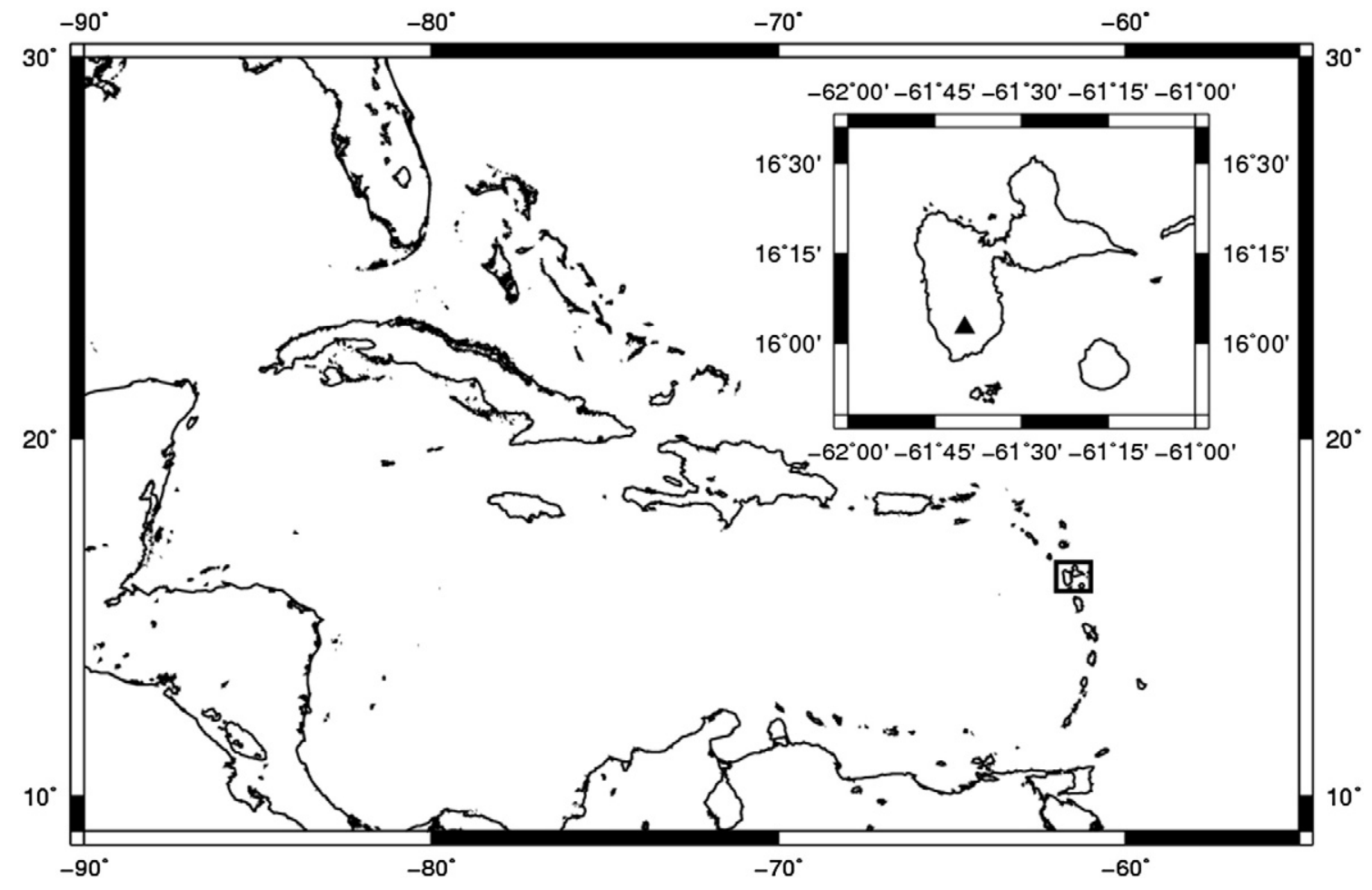

Fig. 1. Localization of "La Soufrière" volcano within the Guadeloupe archipelago, Lesser Antilles arc. 


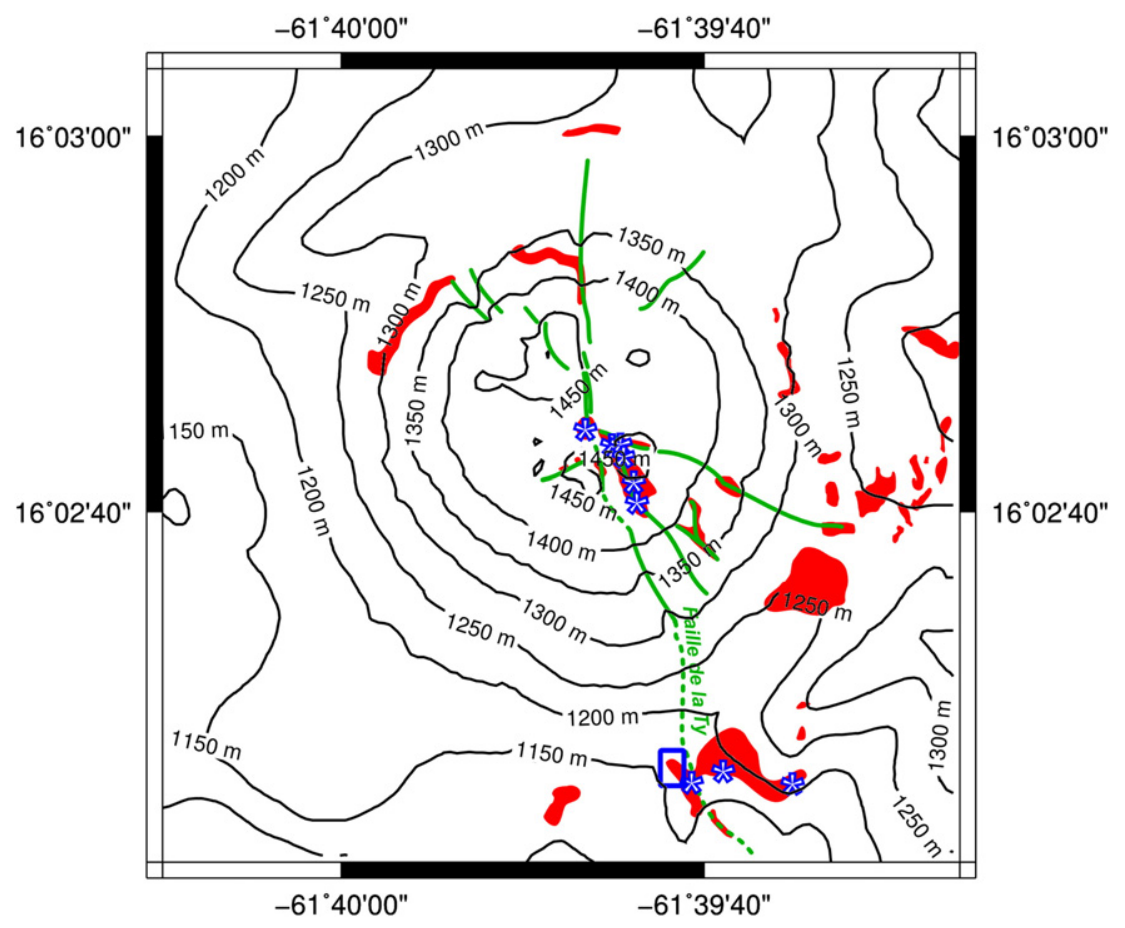

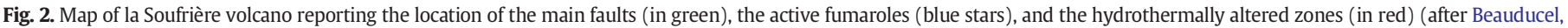
2001; Nicollin et al., 2006). The study area is represented by the blue rectangle, and the profile of Fig. 3 corresponds to the black dotted line. The map is 2 km wide.

The total heat flux from the surface to the atmosphere $\left(\varphi_{\text {tot }}\right)$ is then (Sekioka and Yuhara, 1974; Harris et al., 2009):

$\varphi_{\mathrm{tot}}=\varphi_{\mathrm{r}}+\varphi_{\mathrm{s}}+\varphi_{\mathrm{v}}$

At steady state, this flux is the sum of the geothermal flux $\left(\varphi_{\mathrm{g}}\right)$ and flux due to sun heating. In order to remove this last component, the heat flux of a reference surface outside of the temperature anomaly $\left(\varphi_{\text {ref }}\right)$ is estimated and removed from the total flux (Sekioka and Yuhara, 1974).

$\varphi_{\mathrm{g}}=\varphi_{\mathrm{tot}}-\varphi_{\mathrm{ref}}=\varphi_{\mathrm{r}}-\varphi_{\mathrm{r}, \mathrm{ref}}+\varphi_{\mathrm{s}}-\varphi_{\mathrm{s}, \mathrm{ref}}+\varphi_{\mathrm{v}}$

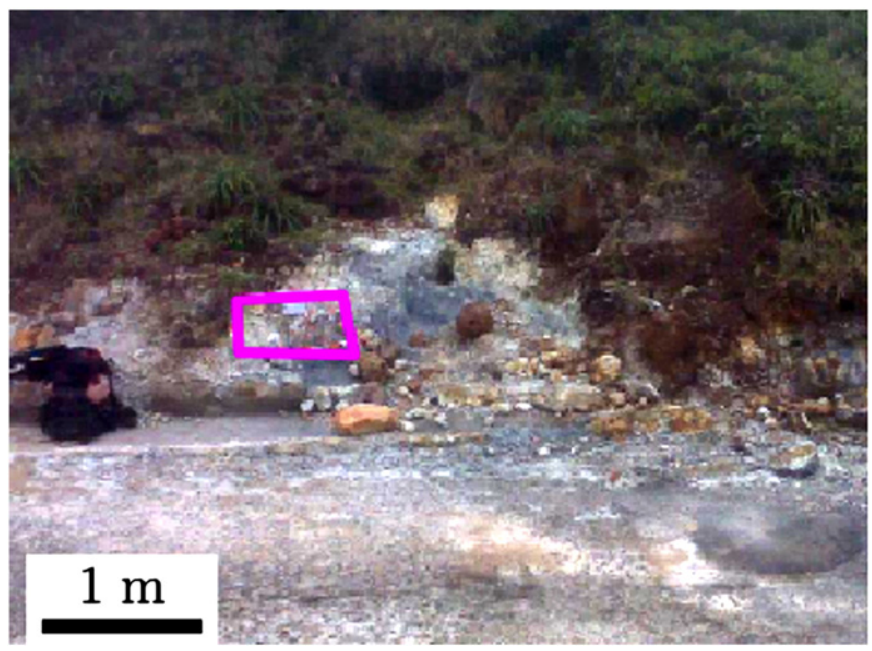

Fig. 3. View of the studied zone, showing the hydrothermal alteration. The area where the geothermal flux has been measured is represented by the magenta rectangle.

\subsection{Excess of radiated flux $\left(\varphi_{r}-\varphi_{r, \text { ref }}\right)$}

The radiated flux is computed from the Stephan-Boltzmann law (Sekioka and Yuhara, 1974; Neri, 1998; Harris et al., 2009; Spampinato et al., 2011). Including the emissivity effect, the excess of radiated flux leaving the studied surface compared to the reference one is:

$\varphi_{\mathrm{r}}=\varepsilon \cdot \sigma \cdot\left[\left(T_{0}+\Delta T\right)^{4}-T_{0}^{4}\right]$

where $\Delta T$ is the temperature contrast between the studied surface and the reference one at the temperature $T_{0}$.

Fig. 4 shows that the excess of radiated flux is primarily dependent on the temperature anomaly. At $20^{\circ} \mathrm{C}$, a temperature contrast of $10^{\circ} \mathrm{C}$ corresponds to an excess of radiated flux of $60 \mathrm{~W} \cdot \mathrm{m}^{-2}$, while a contrast of $50^{\circ} \mathrm{C}$ corresponds to an excess of radiated flux of $360 \mathrm{~W} \cdot \mathrm{m}^{-2}$.

Table 1

Notations and symbols.

\begin{tabular}{|c|c|}
\hline$B(T)$ & Luminance of a blackbody, from 8 to $14 \mu \mathrm{m}\left[\mathrm{W} \cdot \mathrm{m}^{-2} \cdot \mathrm{sr}^{-1}\right]$ \\
\hline$c_{\mathrm{S}}$ & Heat capacity of stram $\left[2080 \mathrm{~J} \cdot \mathrm{kg}^{-1} \cdot \mathrm{K}^{-1}\right]$ \\
\hline$c_{\mathrm{L}}$ & Vaporization latent heat of water $\left[2.25 \times 10^{6} \mathrm{~J} \cdot \mathrm{kg}^{-1}\right.$ at $\left.100^{\circ} \mathrm{C}\right]$ \\
\hline$p_{\text {bo }}$ & Pressure at the boiling point $\left[\mathrm{N} \cdot \mathrm{m}^{-2}\right]$ \\
\hline$p_{\mathrm{v}}$ & Partial pressure of water $\left[\mathrm{N} \cdot \mathrm{m}^{-2}\right]$ \\
\hline$T_{\mathrm{b}}$ & Brightness temperature $[\mathrm{K}]$ \\
\hline$T_{\mathrm{bo}}$ & Temperature of the boiling point [K] \\
\hline$T_{0}$ & Reference temperature (off the anomaly) [K] \\
\hline$T_{\mathrm{s}}$ & Surface temperature $[\mathrm{K}]$ \\
\hline$z_{0}$ & Roughness height [m] \\
\hline$z_{\mathrm{OH}}$ & Characteristic length of the temperature profile [m] \\
\hline$z_{0 \mathrm{M}}$ & Characteristic length of the wind profile $[\mathrm{m}]$ \\
\hline$\varepsilon$ & Emissivity of the surface \\
\hline$\varphi_{\mathrm{g}}$ & Geothermal flux $\left[\mathrm{W} \cdot \mathrm{m}^{-2}\right]$ \\
\hline$\varphi_{\mathrm{r}}$ & Radiated flux $\left[\mathrm{W} \cdot \mathrm{m}^{-2}\right]$ \\
\hline$\varphi_{\mathrm{s}}$ & Sensible flux $\left[\mathrm{W} \cdot \mathrm{m}^{-2}\right]$ \\
\hline$\varphi_{\mathrm{v}}$ & Steam flux $\left[\mathrm{W} \cdot \mathrm{m}^{-2}\right]$ \\
\hline$\sigma$ & Stefan-Boltzmann constant $\left[5.67 \times 10^{8} \mathrm{~J} \cdot \mathrm{K}^{-1}\right]$ \\
\hline$\tau$ & Transmittance of the atmosphere \\
\hline
\end{tabular}




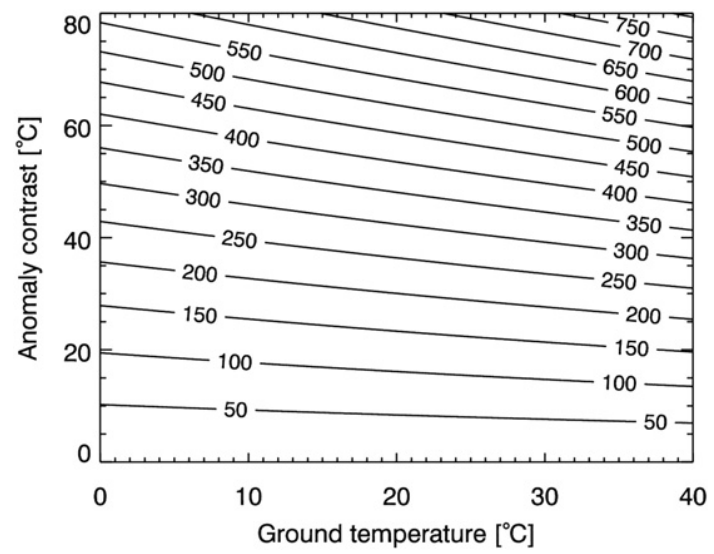

Fig. 4. Excess radiated flux (in $\mathrm{W} \cdot \mathrm{m}^{-2}$ ) according to the temperature anomaly and the reference temperature. Due to the form of Eq. (3), the surfaces flux is greater for high anomalies contrasts, but also for higher surface temperature.

\subsection{Sensible flux $\left(\varphi_{s}\right)$}

The surface is also cooled by the transport of energy through the movements of the atmosphere driven by the regional winds (forced convection) or, more rarely, by the winds due to the thermal expansion of heated atmosphere by the hot surface (free convection) (Sekioka and Yuhara, 1974; Högström, 1988; Neri, 1998). In this study, we mainly focus on forced convection, since 1) the equations of free convection are worse calibrated than the equations of forced convection (Sekioka and Yuhara, 1974; Beljaars, 1995), and 2) free convection occurs only when the wind is very low, as seldom observed at La Soufrière volcano.

The amount of heat transported by wind is called "sensible flux", whose intensity is controlled by the wind characteristics and turbulences due to the interaction between wind and surface relief. It has been demonstrated that rough surfaces generate more turbulence than smooth ones and can increase by a factor 4 the cooling of the surface (Neri, 1998). Two independent formulations of sensible flux taking into account the surface roughness have been previously described.

The first one has been elaborated from wind tunnel experiments in laboratory, and relates sensible flux to roughness and wind velocity (Schlichting, 1968, adapted by Neri, 1998):

$\varphi_{\mathrm{s}} \approx 1500 \cdot u \cdot\left(T(z)-T_{\mathrm{s}}\right) \cdot\left[0.27+1.62 \cdot \log \left(z / z_{0}\right)\right]^{-2.5}$

where $T(z)$ is the atmosphere temperature measured at a height $z$, $u$ the wind velocity at the same height and $T_{\mathrm{s}}$ the surface temperature. $z_{0}$ is a length characterizing the mean roughness height. This model has been tested only on small roughness $\left(z_{0} \leq 1 \mathrm{~cm}\right)$ (Schlichting, 1968; Neri, 1998).

The sensible flux can also be estimated a from micro-meteorological formulation, which is briefly described in Appendix A. This empirical relationship has been widely used, for example in Högström (1988), for a large range of surface roughness. However, this relation has not been designed for large thermal anomalies.

These two models produce similar results for low roughness ( $1 \mathrm{~mm}$ ) (Fig. 5). However, for larger roughness, the results of the two models diverge strongly, probably because the physical model has not been tested on large roughness. The excess of sensible flux $\left(\varphi_{\mathrm{s}}-\varphi_{\mathrm{s}, \mathrm{ref}}\right)$ is computed by subtracting the sensible flux of a zone without geothermal flux to the flux computed on the anomaly.

\subsection{Surface steam flux $\left(\varphi_{v}\right)$}

The gas emitted from fumarolic zones transports an amount of heat that has to be quantified, but this task relies on a precise measure of gas flow and temperature. A first order estimation based on thermodynamical constraints can be done by considering the gas is mainly composed of water steam (Aubert, 1999; Aubert et al., 2008; Antoine et al., 2009). The heat flux is considered to be at steady state, and heat can be carried both by the steam convection through rock permeability and by conduction.

At depth, heat is transported only by gas convection through rock permeability. Consequently, the thermal gradient vanishes in this layer. Close to the surface in the thermal boundary layer, rock temperature decreases toward the surface. Heat is transported by gas convection in the permeability and conduction in rocky matrix. During the ascent toward the surface, part of the steam condensates and produces heat that is transported by conduction.

According to Darcy Law, if the characteristics of the rocks (permeability, porosity) are constant in the thermal boundary layer, the velocity of gas remains constant at steady-state (Lowell, 1991; Rabinowicz et al., 1999; Luna et al., 2002). Partial pressure of water will be close to the saturation vapor pressure, which depends on temperature and can be estimated by Rankine formula (e.g. Pruppacher et al., 1998):

$p_{\mathrm{v}}=p_{\mathrm{bo}} \cdot \exp \left[\left(5120 / T_{\mathrm{bo}}\right)-(5120 / T)\right]$.

$T_{\text {bo }}$ and $p_{\text {bo }}$ represent the temperature and pressure of the boiling point of water in the conditions of the experiment. According to this simple model, gas will escape the surface with a temperature equal to the soil temperature measured by the infrared camera.

Assuming a constant rise velocity of the steam, the ratio of the mass flux at a given depth to its value at the boiling point $M F_{\mathrm{v}} / M F_{\mathrm{bo}}$ is computed from the ratio of $p_{\mathrm{v}} / p_{\text {bo }}$ by simply taking into account the thermal expansion, as:

$M F_{\mathrm{v}} / M F_{\mathrm{bo}}=\left(p_{\mathrm{v}} / p_{\mathrm{bo}}\right) /\left(T_{\mathrm{v}} / T_{\mathrm{bo}}\right)$

From this equation, the ratio of heat flow is computed, by considering the sensible heat and vaporization latent heat of the steam.

$\varphi_{\mathrm{v}} / \varphi_{\mathrm{g}}=\frac{c_{\mathrm{L}}+c_{\mathrm{s}} *\left(T-T_{\mathrm{atm}}\right)}{c_{\mathrm{L}}+c_{\mathrm{s}} *\left(T_{\mathrm{bo}}-T_{\mathrm{atm}}\right)} \cdot \exp \left[\frac{5120}{T_{\mathrm{bo}}}-\frac{5120}{T}\right] \cdot \frac{T_{\mathrm{bo}}}{T_{\mathrm{v}}}$

This ratio is presented on Fig. 6 for different surface temperatures. For a surface temperature of $40^{\circ} \mathrm{C}$, less than $7 \%$ of heat is transported by gas. For surface temperatures higher than $60{ }^{\circ} \mathrm{C}$, this ratio exceeds $20 \%$ and the steam flux should be measured by dedicated methods.

\section{Validation of the method: experiment at the Ty Fault (Guadeloupe)}

In order to test the accuracy of our method, we compared the flux estimated by the thermal infrared method and by the vertical gradient method in a series of 6 experiments at the Ty Fault (Fig. 7) on March 8, 9, 10, 11, 12 and 17, 2012 at different hours of the day (Table 2). The observed variation of activity of the zone occurs in a few years, and will be considered as constant during the time of the study.

\subsection{Thermal infrared measurements}

Thermal surface measurements have been achieved with a Fluke Ti32 uncooled thermal infrared camera (Fig. 8). This camera uses microbolometers whose resistivity is a function of the intensity of incoming radiations between 8 and $14 \mu \mathrm{m}$. The Fluke Ti32 has a 320 by 240 pixel definition, and a temperature resolution of $0.045{ }^{\circ} \mathrm{C}$. The lens has a 23 by $17^{\circ}$ swath. At $15 \mathrm{~m}$ from the target, it allows measurements with a spatial resolution of $2 \mathrm{~cm}$ and a spatial coverage of $6 \mathrm{~m}$.

The camera is calibrated before and after the experiment, with a variable temperature target (Appendix B). In addition, an automatized non-uniformity correction (NUC) corrects the individual drift of single 

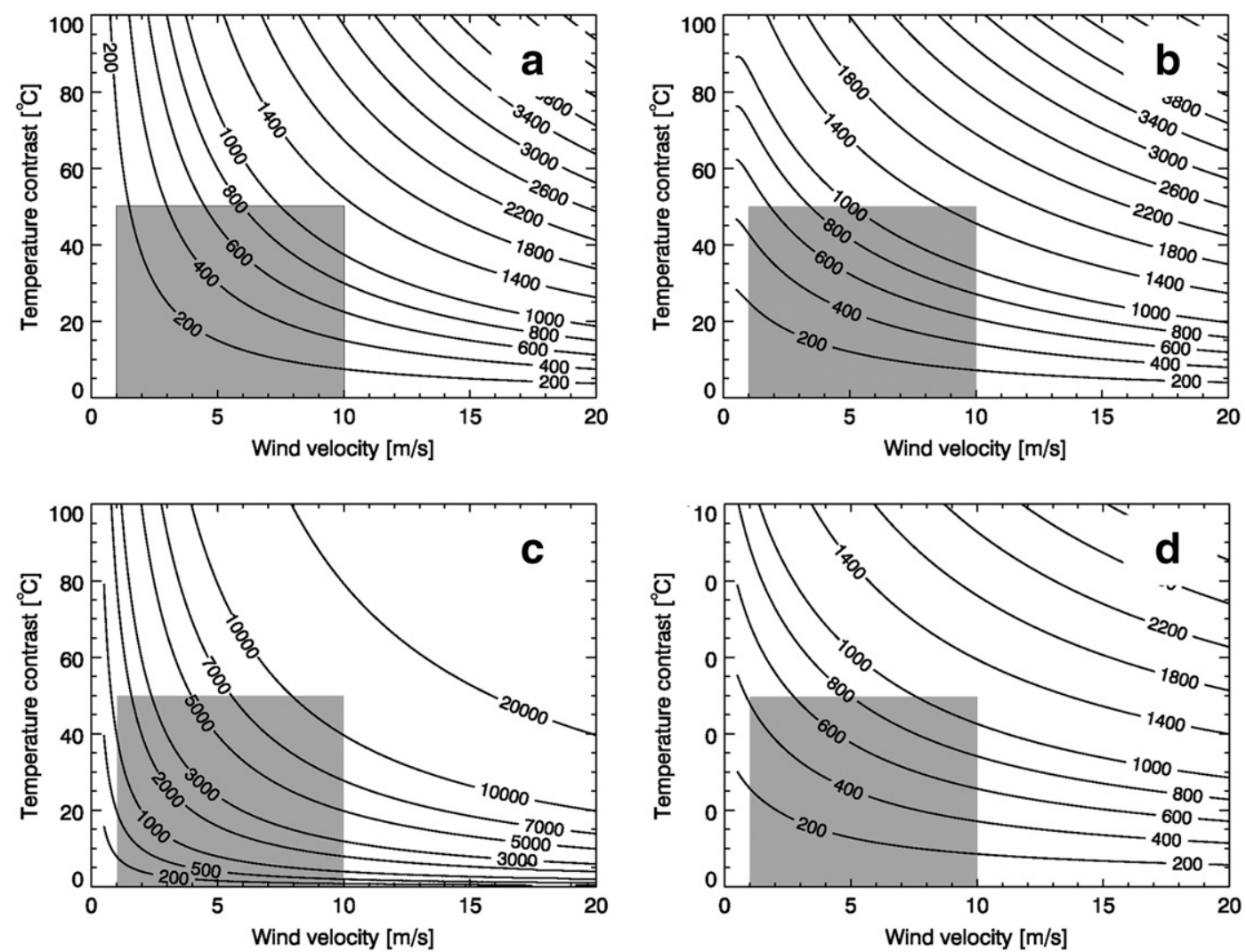

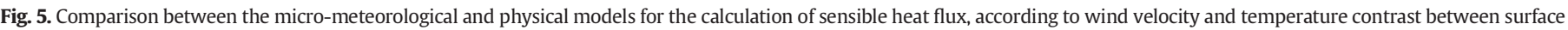

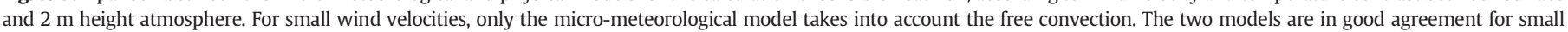

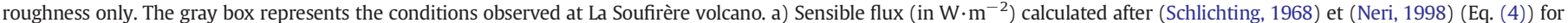

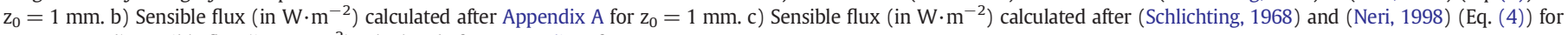
$\mathrm{z}_{0}=10 \mathrm{~cm}$. d) Sensible flux (in $\mathrm{W} \cdot \mathrm{m}^{-2}$ ) calculated after Appendix A for $\mathrm{z}_{0}=10 \mathrm{~cm}$.

microbolometers, which limits the errors on the temperature contrasts within a single image to $0.2 \mathrm{~K}$.

The images are corrected from the atmospheric effects using the MODTRAN4 program (Kneizys et al., 1983; Berk, 1989; Berk et al., 1999). This correction mainly depends on the distance from the target to the camera, the temperature and the humidity content of the atmosphere. These parameters have been measured both before and after each experiment. Since the distance from the surface to the sensor is small $(15 \mathrm{~m})$, constant atmospheric conditions can be assumed. For long range measurements, one might consider a constant relative

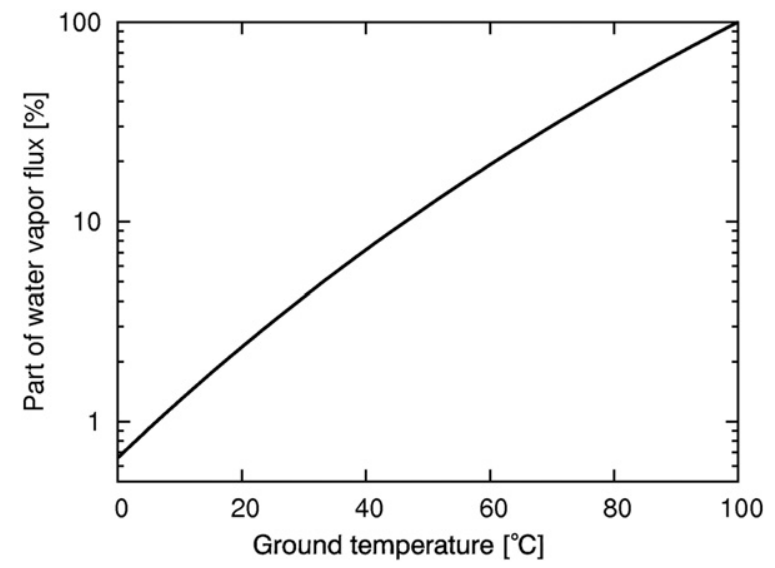

Fig. 6. Proportion of heat flux transported by steam, according to the temperature, at sea level. The hotter is the temperature, the higher is the partial pressure in the steam, and the greater is the geothermal flux. humidity and a vertical temperature gradient of $6{ }^{\circ} \mathrm{C} \cdot \mathrm{km}^{-1}$ in the lower troposphere (NASA, 1976).

The images are finally corrected from the emissivity effects. Indeed, the radiance measured by a camera $L$ is a function of the temperature of the body $(T)$, the emissivity $\varepsilon$ and the downwelling atmosphere radiance $L_{\text {inc }}$, through the equation (Buongiorno et al., 2002):

$L=\varepsilon \cdot B(T)+(1-\varepsilon) \cdot L_{\text {inc }}$

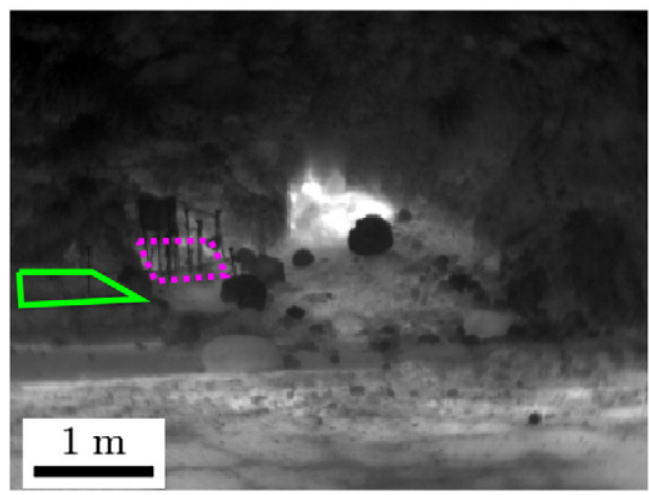

Fig. 7. Study area as seen by the Fluke Ti32 thermal infrared camera. On this raw image without any surface or atmospheric correction, thermal anomalies are clearly visible. The zone in dotted magenta is the zone where the thermocouples have been set up (see Fig. 9). The green solid line zone is the reference zone, where the geothermal flux is considered as negligible. 
Table 2

Geothermal flux at the Ty Fault estimated by the thermal infrared method. The mean retrieved flux is $267 \pm 46 \mathrm{~W} \cdot \mathrm{m}^{-2}$

\begin{tabular}{|c|c|c|c|c|c|c|}
\hline Date & 08/03/2012 & 09/03/2012 & $10 / 03 / 2012$ & $11 / 03 / 2012$ & $12 / 03 / 2012$ & $17 / 03 / 2012$ \\
\hline Hour (TU) & $18: 30$ & $17: 30$ & $14: 00$ & $16: 20$ & $12: 30$ & $21: 30$ \\
\hline Surface temperature & $27.7^{\circ} \mathrm{C}$ & $28.6^{\circ} \mathrm{C}$ & $28.4^{\circ} \mathrm{C}$ & $24.8^{\circ} \mathrm{C}$ & $28.9^{\circ} \mathrm{C}$ & $28.5^{\circ} \mathrm{C}$ \\
\hline Reference temperature & $24.0^{\circ} \mathrm{C}$ & $25.1^{\circ} \mathrm{C}$ & $23.2^{\circ} \mathrm{C}$ & $20.6^{\circ} \mathrm{C}$ & $24.2^{\circ} \mathrm{C}$ & $24.1^{\circ} \mathrm{C}$ \\
\hline Atmosphere temperature & $20.4^{\circ} \mathrm{C}$ & $21.0^{\circ} \mathrm{C}$ & $18.1^{\circ} \mathrm{C}$ & $19.2^{\circ} \mathrm{C}$ & $18.7^{\circ} \mathrm{C}$ & $17.3^{\circ} \mathrm{C}$ \\
\hline Wind velocity $(2 \mathrm{~m})$ & $2.8 \mathrm{~m} \cdot \mathrm{s}^{-1}$ & $2.0 \mathrm{~m} \cdot \mathrm{s}^{-1}$ & $1.4 \mathrm{~m} \cdot \mathrm{s}^{-1}$ & $1.5 \mathrm{~m} \cdot \mathrm{s}^{-1}$ & $1.9 \mathrm{~m} \cdot \mathrm{s}^{-1}$ & $1.7 \mathrm{~m} \cdot \mathrm{s}^{-1}$ \\
\hline Radiated flux & $22 \mathrm{~W} \cdot \mathrm{m}^{-2}$ & $22 \mathrm{~W} \cdot \mathrm{m}^{-2}$ & $31 \mathrm{~W} \cdot \mathrm{m}^{-2}$ & $25 \mathrm{~W} \cdot \mathrm{m}^{-2}$ & $29 \mathrm{~W} \cdot \mathrm{m}^{-2}$ & $27 \mathrm{~W} \cdot \mathrm{m}^{-2}$ \\
\hline Sensible flux & $301 \mathrm{~W} \cdot \mathrm{m}^{-2}$ & $207 \mathrm{~W} \cdot \mathrm{m}^{-2}$ & $211 \mathrm{~W} \cdot \mathrm{m}^{-2}$ & $185 \mathrm{~W} \cdot \mathrm{m}^{-2}$ & $271 \mathrm{~W} \cdot \mathrm{m}^{-2}$ & $218 \mathrm{~W} \cdot \mathrm{m}^{-2}$ \\
\hline Steam flux fraction & $2.8 \%$ & $3.0 \%$ & $3.0 \%$ & $2.2 \%$ & $3.1 \%$ & $3.0 \%$ \\
\hline Surface flux retrieved & $332 \mathrm{~W} \cdot \mathrm{m}^{-2}$ & $236 \mathrm{~W} \cdot \mathrm{m}^{-2}$ & $249 \mathrm{~W} \cdot \mathrm{m}^{-2}$ & $214 \mathrm{~W} \cdot \mathrm{m}^{-2}$ & $309 \mathrm{~W} \cdot \mathrm{m}^{-2}$ & $252 \mathrm{~W} \cdot \mathrm{m}^{-2}$ \\
\hline
\end{tabular}

where $B(T)$ represents the Planck law. We assumed a Lambertian reflection (e.g. Sekioka and Yuhara, 1974; Friedman et al., 1982; Oppenheimer, 1993), and used a averaged value derived from literature (Sekioka and Yuhara, 1974; Taylor, 1979; Buongiorno et al., 2002; Ball and Pinkerton, 2006) of 0.95. The downwelling radiance is measured with the thermal camera at the beginning and at the end of the experiment.

Finally, the measurements have been averaged on $1 \mathrm{~m}^{2}$, for both the studied surface and the reference surface where the geothermal flux is assumed to be negligible.

\subsection{Atmospheric measurements}

Sensible flux computation requires wind and temperature measurements at a given height, set here at $2 \mathrm{~m}$ from the ground. These parameters have been measured with a Testo 410-2 flow/ humidity/temperature gauge (see Fig. 8). The precisions are $0.2 \mathrm{~m} \cdot \mathrm{s}^{-1}$ for the wind, $0.5 \mathrm{~K}$ for the temperature. Measurements have been averaged over $10 \mathrm{~min}$.

\subsection{Vertical temperature profile measurement}

The vertical temperature profiles were measured by 8 pairs of thermocouples set up at 5, 10,15, 20, 25, 30, 40 and $50 \mathrm{~cm}$ depth (Fig. 9) for the time of the experiment. No significant variation of the measured temperature was noticed during the $10 \mathrm{~min}$ of the measurements, and the precision of a single thermocouple is about $1 \mathrm{~K}$. However, due to the lateral heterogeneity of the temperature the mean deviation between two thermometers at the same depth is about $3 \mathrm{~K}$.

\subsection{Estimation of the surface roughness length $\left(z_{0}\right)$}

The surface roughness is defined after Schlichting (1968) and Lettau (1969) as the mean height of the obstacles on the surface. In our case, $z_{0}$ represents the mean amplitude of the relief, estimated on a profile of $5 \mathrm{~m}$ parallel to the wind direction. However, the retrieved value $\left(z_{0} \approx 10 \mathrm{~cm}\right)$ has a great degree of uncertainty.

\section{Results and comparison of the two methods}

The 6 experiments were performed at various hours of the day, in conditions of weak or null rain within the last $24 \mathrm{~h}$ (precipitations $<5 \mathrm{~mm}$ ). Air temperature varied from 17.3 to $21.0^{\circ} \mathrm{C}$ and wind velocity ranged from 1.4 to $2.8 \mathrm{~m} \cdot \mathrm{s}^{-1}$. For each of the six observations, the geothermal flux was estimated both by measuring the vertical temperature gradient (Fig. 10) and by thermal infrared remote sensing (Table 2 ).

The heat flux was derived from the micro-meteorological formulation, which has been more specifically designed to low-wind and high-roughness conditions than the wind tunnel one. It ranged from 217 to $336 \mathrm{~W} \cdot \mathrm{m}^{-2}$ with an average value of $267 \pm 46 \mathrm{~W} \cdot \mathrm{m}^{-2}$.

\section{Temperature measurement by thermal infrared imagery}

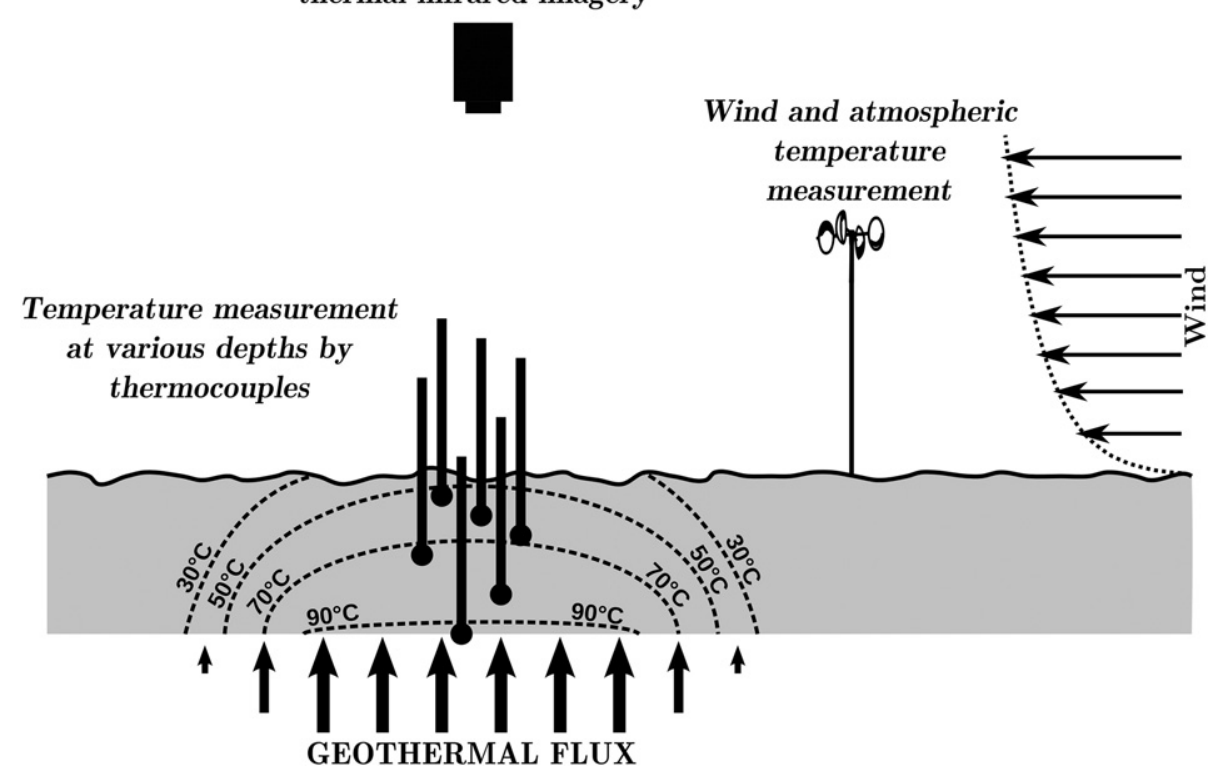

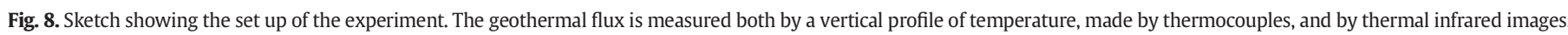
Atmosphere temperature and wind velocity are measured. 


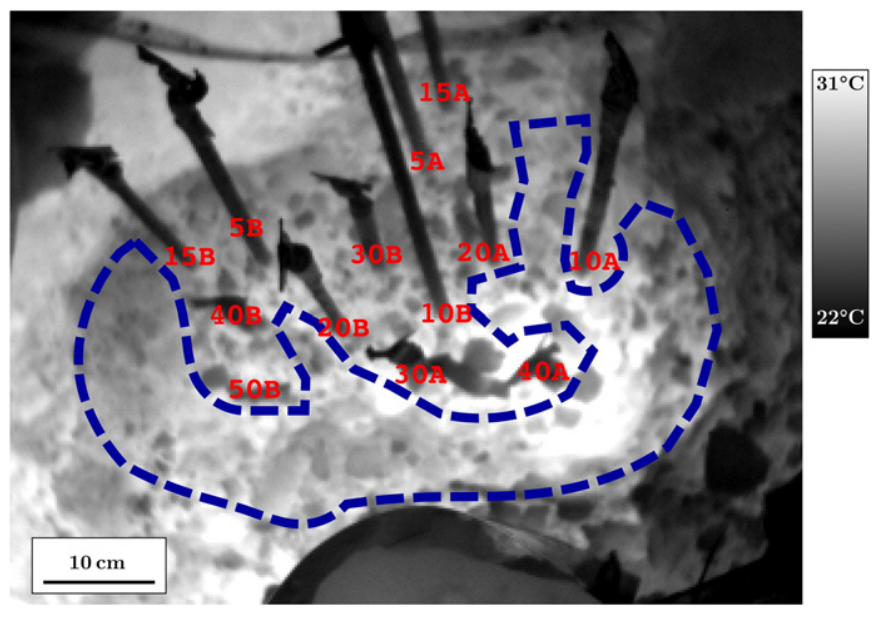

Fig. 9. Closer thermal infrared view of the study area, showing the thermal anomaly and the thermocouples (cooler than the surroundings). The numbers in red indicate the depth of the thermometers in centimeters. Surface temperature is computed as the mean of the blue dotted line (surface not hidden by the thermocouples).

The sensible flux was estimated to represent more than $80 \%$ of the total flux. Despite these variations, the variability of heat flux around the average is less than $20 \%$ indicating that the method is robust.

The vertical temperature profiles are similar for the 6 experiments (temperature variation at a given depth are less than $1 \mathrm{~K}$ ). In order to compute the geothermal flux from the vertical temperature profile, we assume that steam flows upward at a constant velocity (Eq. (6)). The total heat flux is the sum of conduction and the steam flux:

$\varphi=-k \cdot \frac{d T}{d z}+\varphi \cdot \frac{c_{\mathrm{L}}+c_{\mathrm{s}} \cdot\left(T-T_{\mathrm{atm}}\right)}{c_{\mathrm{L}}+c_{\mathrm{s}} \cdot\left(T_{\mathrm{bo}}-T_{\mathrm{atm}}\right)} \cdot \exp \left[\frac{5120}{T}-\frac{5120}{T_{\mathrm{bo}}}\right] \cdot \frac{T_{\mathrm{bo}}}{T}$

where $T_{\mathrm{bo}}$ is the boiling point of water and $k$ represents here the thermal conductivity of the soil and $T$ the temperature at the depth $z$. This conductivity is typically $1 \mathrm{~W} \cdot \mathrm{m} \cdot{ }^{-1} \cdot \mathrm{K}^{-1}$ for terrestrial materials, including silts and water (Smith, 1942). Theoretical profiles have been computed in Fig. 11 and compared to the measured profiles. The geothermal flux, according to this method, is $275 \pm 50 \mathrm{~W} \cdot \mathrm{m}^{-2}$.

Table 2 shows that, despite variable atmospheric conditions, fluxes measured from thermal infrared images are very consistent all together. The measured flux $\left(267 \pm 46 \mathrm{~W} \cdot \mathrm{m}^{-2}\right)$ is comparable with the value found with the vertical temperature gradient method.

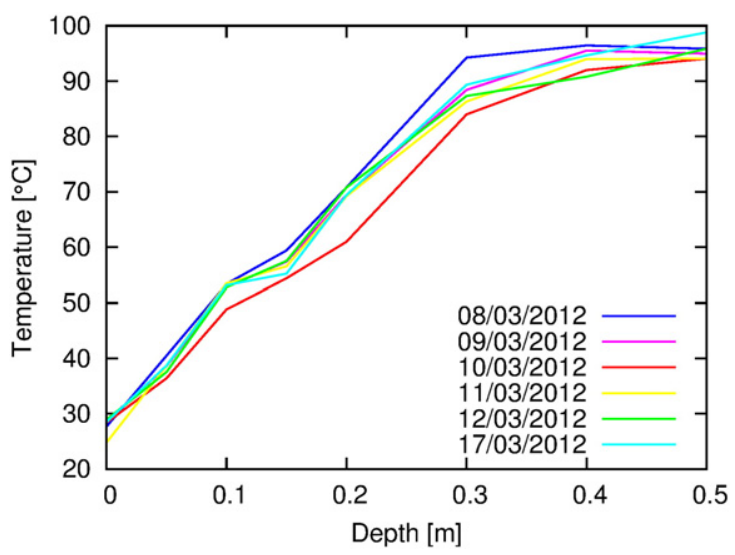

Fig. 10. Measured temperature profiles. Each measure is provided by a couple of thermocouples located at $5,10,15,20,25,30,40$ and $50 \mathrm{~cm}$. These measurements have been done with weak or null rain within the last $24 \mathrm{~h}$ (precipitations $<5 \mathrm{~mm}$ ). The retrieved flux is $275 \pm 50 \mathrm{~W} \cdot \mathrm{m}^{-2}$.

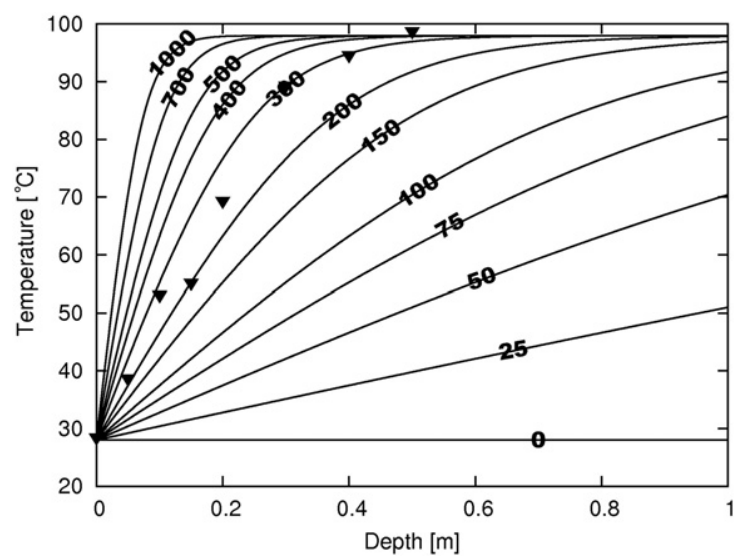

Fig. 11. Theoretical and measured profiles of temperature. Theoretical profiles have been computed by the numerical integration of the Eq. (9), assuming a steady state. The real profile has been measured on the $17 / 03 / 2012$, with the series of thermocouples described above. The total heat flux is here $275 \pm 50 \mathrm{~W} \cdot \mathrm{m}^{-2}$.

\section{Discussion}

The conversion of a thermal anomaly to a heat flux is very dependent on the used model (Fig 5). For low values of the geothermal flux, the sensible flux represents more $80 \%$ of the total flux. The robustness of the sensible flux model used is then a key point on the final accuracy. Because of the constraints on meteorological conditions for thermal infrared measurements (no clouds or fog, and humidity as low as possible), the model could not be tested on a large range of field condition on La Soufrière volcano. Consequently, the accuracy had to be estimated by comparing two independent models. Models are in very good agreement in the case of smooth surfaces, differences not exceeding $15 \%$ in the case of forced convection (Fig. 5), even for large temperature contrasts. However, for rough surfaces, the two models strongly diverge. The model of Schlichting (1968), adapted by Neri (1998) suggest an increase of the sensible flux by a factor of 10 when increasing the surface roughness from $1 \mathrm{~mm}$ to $10 \mathrm{~cm}$, while according to the micrometeorological models, this increase is only of a factor of 2. However, the Schlichting (1968) model has not been tested for roughness above $1 \mathrm{~cm}$ (Neri, 1998), so the micrometeorological model should be used for such roughness.

The steam flux is estimated through a first order model, considering a constant ascent velocity of the steam and steady state of the flux. The constant ascent velocity hypothesis is based on numerical models assuming steady-state (Lowell, 1991; Rabinowicz et al., 1999; Luna et al., 2002), and constant physical parameters. It is supported by the good fit between the measured vertical temperature profiles and the theory based on this assumption (Fig. 11). Furthermore, the fluxes computed from this model are close $(<20 \%$ error) to the flux computed by the conduction equation close to the surface. Thus, this simple model seems to suit well low flux geothermal areas where the steam flux has a minor contribution to the total surface flux. Deeper studies would be required in order to extend the use of this model for fluxes above $500 \mathrm{~W} \cdot \mathrm{m}^{-2}$ (corresponding to a surface temperature higher than $\left.40^{\circ} \mathrm{C}\right)$.

To ensure that the surface flux is representative of the geothermal flux, the system must be at steady-state. Since the effects of sun heating are removed with the reference surface, the steady state can only be disturbed by 1) a fast variation of the geothermal flux, 2) rainfall events. Unpublished measurements on the Ty Fault (Finizola, personal communication) as well as studies on other volcanoes (Harris et al., 2009) shows that after a perturbation, the systems comes back to steady state in a few days. In our case, the qualitative observation of the fumaroles by the OVSG-IPGP (2012) suggests that the geothermal flux changes at time scale of a few years, and can be considered as constant within a few days. In addition, measurements were achieved at least a 
Table 3

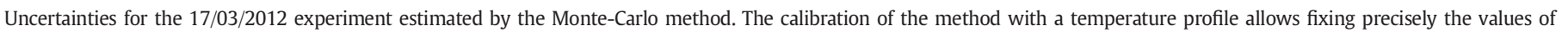
roughness and emissivity. The uncertainties are thus significantly reduced.

\begin{tabular}{|c|c|c|c|}
\hline & Value & Uncertainties & Uncertainties after calibration \\
\hline Brightness temperature of anomaly & $28.5^{\circ} \mathrm{C}$ & $\pm 2{ }^{\circ} \mathrm{C}$ & $\pm 2{ }^{\circ} \mathrm{C}$ \\
\hline Reference brightness temperature & $24.1^{\circ} \mathrm{C}$ & $\pm 2^{\circ} \mathrm{C}$ & $\pm 2{ }^{\circ} \mathrm{C}$ \\
\hline Atmosphere temperature & $17.3^{\circ} \mathrm{C}$ & $\pm 1{ }^{\circ} \mathrm{C}$ & $\pm 1{ }^{\circ} \mathrm{C}$ \\
\hline Emissivity & 0.95 & \pm 0.05 & l \\
\hline Transmittance & 1.00 & \pm 0.01 & \pm 0.01 \\
\hline Wind velocity ( $2 \mathrm{~m}$ height) & $1.7 \mathrm{~m} \cdot \mathrm{s}^{-1}$ & $\pm 0.3 \mathrm{~m} \cdot \mathrm{s}^{-1}$ & $\pm 0.3 \mathrm{~m} \cdot \mathrm{s}^{-1}$ \\
\hline Roughness $\left(z_{0}\right)$ & $0.12 \mathrm{~m}$ & $\pm 0.10 \mathrm{~m}$ & / \\
\hline Estimated anomaly temperature & $25.5^{\circ} \mathrm{C}$ & $\pm 5^{\circ} \mathrm{C}$ & $\pm 5^{\circ} \mathrm{C}$ \\
\hline Estimated reference temperature & $21.1^{\circ} \mathrm{C}$ & $\pm 5^{\circ} \mathrm{C}$ & $\pm 5^{\circ} \mathrm{C}$ \\
\hline Estimated difference of temperature & $4.4^{\circ} \mathrm{C}$ & $\pm 0.2^{\circ} \mathrm{C}$ & $\pm 0.2^{\circ} \mathrm{C}$ \\
\hline Radiated flux (Eq. (3)) & $27 \mathrm{~W} \cdot \mathrm{m}^{-2}$ & $\pm 10 \mathrm{~W} \cdot \mathrm{m}^{-2}$ & $\pm 10 \mathrm{~W} \cdot \mathrm{m}^{-2}$ \\
\hline Sensible flux (Eq. (4)) & $218 \mathrm{~W} \cdot \mathrm{m}^{-2}$ & $\pm 140 \mathrm{~W} \cdot \mathrm{m}^{-2}$ & $\pm 44 \mathrm{~W} \cdot \mathrm{m}^{-2}$ \\
\hline Steam flux proportion (Eq. (7)) & $3 \%$ & $\pm 0.3 \%$ & $\pm 0.3 \%$ \\
\hline Total flux & $252 \mathrm{~W} \cdot \mathrm{m}^{-2}$ & $\pm 149 \mathrm{~W} \cdot \mathrm{m}^{-2}$ & $\pm 53 \mathrm{~W} \cdot \mathrm{m}^{-2}$ \\
\hline
\end{tabular}

two days after the last rainfall event to ensure that the steady state assumption is valid.

For a defined model, the most important source of error is the estimation of the roughness length $z_{0}$ (Table 3 ) which strongly varies in literature (see the discussions in Schlichting, 1968; Lettau, 1969; Counehan, 1971; MacDonald et al., 1998). Future studies on this topic may dramatically improve the precision of this method. Currently, $z_{0}$ should be calibrated in the field, by comparing the vertical temperature gradient method and the thermal infrared method in a few points to get the most precise estimates. This calibration reduces the error from $60 \%$ to $20 \%$ of the total flux (Table 3), matching well the vertical profile of temperature results, and corresponding to the error of wind velocity.

\section{Conclusion}

Heat flux can be extracted from thermal infrared images using a set of models describing respectively the emission of the thermal energy in the thermal infrared domain, the sensible heat flux extracted by atmosphere, and the heat flux associated to steam flow. Major uncertainties come from the estimation of the surface roughness and the accuracy of the models, and may be dramatically improved by future research on these topics. The experiments conducted on the Ty fault show that, once calibrated, the thermal infrared method provides results similar to those of the classical gradient method, with a similar uncertainty of around $20 \%$ due to the variation of meteorological conditions.

If the geothermal flux evolution is slow, and no rainfall has occurred before the measurements, the surface flux is representative of the geothermal flux. From thermal infrared images, both the localization and the intensity of the geothermal flux can be precisely determined over large areas. Consequently, this method is suitable to the longterm survey of low flux fumarolic zones and could be used as an early warning system for the reactivation of dormant volcanoes.

\section{Acknowledgements}

This work has been supported by the ANR project DOMOSCAN and the TOSCA CNES program "Geomether". The Staff of the "Observatoire volcanologique et sismologique de Guadeloupe" is warmly acknowledged for his efficient support. The authors thank Pascal Brunel for the use of CMS facilities, and Raphaël Antoine for his remarks. This is the IPGP contribution 3445 .

\section{Appendix A. Brief description of micrometeorological models}

Micrometeorological models are based on characteristic scales describing the atmospheric dynamics. A characteristic friction velocity $\left(u^{*}\right)$, a characteristic temperature $\left(T^{*}\right)$ and a characteristic length, called Monin-Obukhov length $\left(L_{\mathrm{MO}}\right)$ are thus defined by the following formulas:

$$
\begin{aligned}
& u_{*}=\frac{\kappa \cdot u(z)}{\log \left(z / z_{0 \mathrm{M}}\right)-\psi_{\mathrm{M}}\left(z / L_{\mathrm{MO}}\right)+\psi_{\mathrm{M}}\left(z_{0 \mathrm{M}} / L_{\mathrm{MO}}\right)} \\
& T_{*}=\frac{\kappa \cdot\left(T(z)-T_{\mathrm{S}}\right)}{0.74 \cdot\left[\log \left(z / z_{0 \mathrm{H}}\right)-\psi_{\mathrm{H}}\left(z / L_{\mathrm{MO}}\right)+\psi_{\mathrm{H}}\left(z_{0 \mathrm{H}} / L_{\mathrm{MO}}\right)\right]} \\
& L_{\mathrm{MO}}=-\frac{u_{*}^{2} \cdot T(z)}{\kappa \cdot g \cdot T_{*}}
\end{aligned}
$$

where $\kappa$ is the Von Kármán constant $(\kappa \approx 0.41)$ (Garratt, 1994; Mascart et al., 1995). $\psi_{\mathrm{M}}$ and $\psi_{\mathrm{H}}$, called similarity functions, relate the fluxes of momentum and sensible heat to their gradients. Their expression is discussed in Högström (1988). Finally, $z_{0 \mathrm{M}}$ and $z_{0 \mathrm{H}}$ are the aerodynamic roughness lengths for momentum and humidity, that characterize the wind and temperature profiles. $z_{0 \mathrm{M}}$ can be linked to the mean height $z_{0}$ of the obstacles on the surface following Lettau (1969):

$z_{0 \mathrm{M}}=0.058 \cdot z_{0}{ }^{1.18}$

$z_{0 \mathrm{H}}$ is derived from $z_{0 \mathrm{M}}$ using a ratio $z_{\mathrm{OH}} / z_{\mathrm{OM}}=0.01$ corresponding to the average value of various studies (Owen and Thomson, 1963; Mascart et al., 1995; Cahill et al., 1997; Verhoef et al., 1997; Blümel, 1999; Su et al., 2001) no consensus appears. In this study, we use a ratio of $1 / 100$, which corresponds to a usual value of some studies. However, this estimation remains a crucial point and it is a source of major uncertainties.

In this formulation (Eqs. (A1)-(A3)), the characteristic numbers are intercorrelated. Consequently, the calculation needs successive iterations (Garratt, 1994). A polynomial fit has been proposed by Mascart et al. (1995) in order to avoid these iterations.

The sensible heat flux is computed from the characteristic length and temperature:

$\varphi_{\mathrm{s}}=\rho_{\mathrm{air}} \cdot c_{\mathrm{air}} \cdot u_{*} \cdot T_{*}$

$\rho_{\text {air }}$ and $c_{\text {air }}$ represents the density and the heat capacity of air $\left(\rho_{\text {air }} \cdot c_{\text {air }} \approx 1200 \mathrm{~J} \cdot \mathrm{K}^{-1} \cdot \mathrm{m}^{-2}\right.$ at $\left.20^{\circ} \mathrm{C}\right)$.

In the cases of weak or null wind velocity, a free convection regime occurs. Air is heated near the surface, and, due to its density decrease, raises in the atmosphere, creating motion. The previous formulation has to be adapted to take into account this phenomenon. Deardorff 


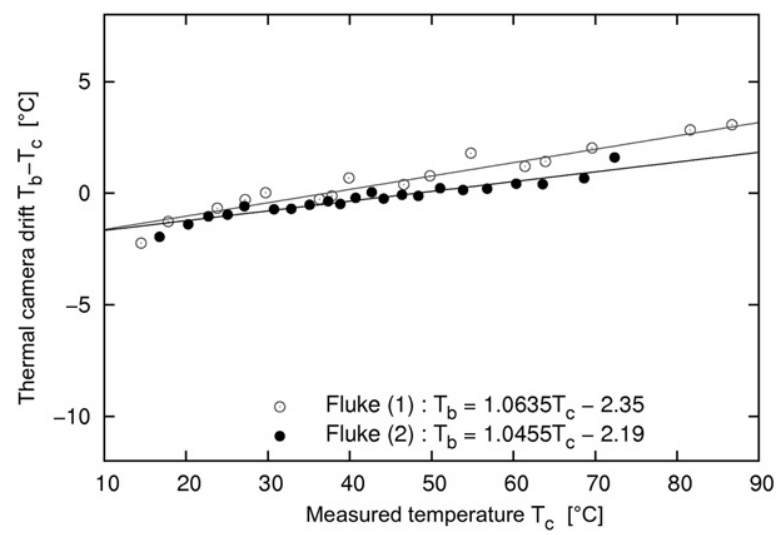

Fig. 12. Calibration curves of the thermal camera, representing the difference between the target real temperature and the measured temperature. The difference from the raw temperature compared to the real one is $5 \mathrm{~K}$. However, the two calibrations curves show a very good agreement together, and the uncertainties are reduced to $2 \mathrm{~K}$ after the calibration.

(1970) redefines $u_{*}$ by adding the value of the wind generated by the free convection to the regional wind:

$$
u_{*}=\frac{\kappa \cdot \sqrt{ }\left[u^{2}(z)+1.2 \cdot\left(1 / 3 \cdot u_{*} \cdot T_{*} \cdot z\right)^{2 / 3}\right]}{\left[\log \left(z / z_{0 \mathrm{M}}\right)-\psi_{\mathrm{M}}\left(z / L_{\mathrm{MO}}\right)+\psi_{\mathrm{M}}\left(z_{0 \mathrm{M}} / L_{\mathrm{MO}}\right)\right]} .
$$

Eq. (A6) is used jointly with Eq. (A2), (A3) and (A5) to compute the sensible flux in all conditions.

\section{Appendix B. Calibration of cameras}

In order to improve the precisions of the temperature measurements, the camera has been calibrated before and after the experiment with a variable temperature target. This source is composed of a brass box containing water whose temperature is easily measurable with a thermocouple (precision of $0.5{ }^{\circ} \mathrm{C}$ ). Furthermore, it is used as a heat reservoir. A thin layer of brass, whose thermal conductivity is high (around $100 \mathrm{~W} \cdot \mathrm{m}^{-1} \cdot \mathrm{s}^{-1}$ ) maintains the surface temperature of the box very close to the water temperature. The difference is lower than $0.05{ }^{\circ} \mathrm{C}$. The box is painted with Nextel Velvet Coating 811-21. This painting, composed of $80 \%$ of silicon dioxide and $20 \%$ of carbon oxide has a high emissivity of 0.98 (Kwor and Matte, 2001; Dury et al., 2007). The brightness temperature is computed after the measurement of environment luminance.

A calibration curve is plotted by varying the surface temperature of the box. For a $100{ }^{\circ} \mathrm{C}$ measurement range, instrumental error is fitted by an affine function. The results of two calibrations are shown on Fig. 12. The calibration reduces the uncertainty of the brightness temperature from $5^{\circ} \mathrm{C}$ to $2^{\circ} \mathrm{C}$.

\section{References}

Allard, P., Hammouya, G., Parello, F., 1998. Dégazage magmatique diffus à la Soufrière de Guadeloupe, Antilles. C. R. Acad. Sci. Ser. IIA-Earth Planet. Sci. 327 (5), 315-318.

Antoine, R., Baratoux, D., Rabinowicz, M., Fontaine, F., Bachèlery, P., Staudacher, T., Saracco, G., Finizola, A., 2009. Thermal infrared image analysis of a quiescent cone on Piton de la Fournaise volcano: evidence of convective air flow within an unconsolidated soil. J. Volcanol. Geotherm. Res. 183 (3-4), 228-244.

Aubert, M., 1999. Practical evaluation of steady heat discharge from dormant active volcanoes: case study of Vulcarolo fissure (Mount Etna, Italy). J. Volcanol. Geotherm. Res. 92 (3-4), 413-429.

Aubert, M., Diliberto, S., Finizola, A., Chébli, Y., 2008. Double origin of hydrothermal convective flux variations in the Fossa of Vulcano (Italy). Bull. Volcanol. 70 (6), 743-751.

Ball, M., Pinkerton, H., 2006. Factors affecting the accuracy of thermal imaging cameras in volcanology. J. Geophys. Res. 111 (B11), B11203.
Baxter, P., Baubron, J.C., Coutinho, R., 1999. Health hazards and disaster potential of ground gas emissions at Furnas volcano, São Miguel, Azores. J. Volcanol. Geotherm. Res. 92 (1-2), 95-106.

Beauducel, F., 2001. High-resolution digital elevation model of La Soufrière lava dome. OVSG database, Institut de Physique du Globe de Paris, Gourbeyre, Guadeloupe, FWI.

Beljaars, A., 1995. The parametrization of surface fluxes in large-scale models under free convection. Q. J. R. Meteorol. Soc. 121 (522), 255-270.

Berk, A., 1989. MODTRAN: a moderate resolution model for LOWTRAN 7. Technical report. Geophysics Laboratory, Air Force Systems Command (44 pp.).

Berk, A., Anderson, G., Bernstein, L., Acharya, P., Dothe, H., Matthew, M., Adler-Golden, S., Chetwynd Jr., J., Richtsmeier, S., Pukall, B., Allredb, C.L., Jeongb, L., Hoke, M., 1999. MODTRAN 4 radiative transfer modeling for atmospheric correction. Proc. SPIE Int. Soc. Opt. Eng. 3756, 348-353.

Blümel, K., 1999. A simple formula for estimation of the roughness length for heat transfer over partly vegetated surfaces. J. Appl. Meteorol. 38 (6), 814-829.

Boudon, G., Komorowski, J., Villemant, B., Semet, M., 2008. A new scenario for the last magmatic eruption of La Soufricre of Guadeloupe (Lesser Antilles) in 1530 AD. Evidence from stratigraphy radiocarbon dating and magmatic evolution of erupted products. J. Volcanol. Geotherm. Res. 178 (3), 474-490.

Brombach, T., Marini, L., Hunziker, J., 2000. Geochemistry of the thermal springs and fumaroles of Basse-Terre Island, Guadeloupe, Lesser Antilles. Bull. Volcanol. 61 (7), 477-490.

Buongiorno, M., Realmuto, V., Fawzi, D., 2002. Recovery of spectral emissivity from thermal infrared multispectral scanner imagery acquired over a mountainous terrain: a case study from Mount Etna Sicily. Remote Sens. Environ. 79, 123-133.

Cahill, A., Parlange, M., Albertson, J., 1997. On the Brutsaert temperature roughness length model for sensible heat flux estimation. Water Resour. Res. 33 (10), 2315-2324.

Counehan, J., 1971. Wind tunnel determination of the roughness length as a function of the fetch and the roughness density of three-dimensional roughness elements. Atmos. Environ. 5 (8), 637-642.

Deardorff, J., 1970. Convective velocity and temperature scales for the unstable planetary boundary layer and for Raleigh convection. J. Atmos. Sci. 27, 1211-1213.

Dury, M., Theocharous, T., Harrison, N., Fox, N., Hilton, M., 2007. Common black coatingsreflectance and ageing characteristics in the $0.32-14.3(\mathrm{mu}) \mathrm{m}$ wavelength range, Opt. Commun. 270 (2), 262-272.

Feuillard, M., Allegre, C., Brandeis, G., Gaulon, R., Le Mouel, J., Mercier, J., Pozzi, J., Semet, M., 1983. The 1975-1977 crisis of La Soufrière de Guadeloupe (FWI): a still-born magmatic eruption. J. Volcanol. Geotherm. Res. 16 (3-4), 317-334.

Feuillet, N., Manighetti, I., Tapponnier, P., 2001. Extension active perpendiculaire à la subduction dans l'arc des Petites Antilles (Guadeloupe, Antilles françaises): active arc-transverse normal faulting in Guadeloupe (French Lesser Antilles). Comptes Rendus de l'Académie des Sciences-Series IIA-Earth and Planetary Science 333 (9), 583-590.

Feuillet, N., Manighetti, I., Tapponnier, P., Jacques, E., 2002. Arc parallel extension and localization of volcanic complexes in Guadeloupe, Lesser Antilles. J. Geophys. Res. 107 (B12), 2331-2360.

Frank, D., 1985. Hydrothermal processes at Mount Rainier, Washington. (PhD thesis) Washington Univ., Seattle (USA) (195 pp.).

Friedman, J., Williams, D., Frank, D., 1982. Structural and heat flow implications of infrared anomalies at Mt. Hood, Oregon, 1972-1977. J. Geophys. Res. 87 (B4), 2793-2803.

Gaonac'h, H., Vandemeulebrouck, J., Stix, J., Halbwachs, M., 1994. Thermal infrared satellite measurements of volcanic activity at Stromboli and Vulcano. J. Geophys. Res. 99 (B5), 9477-9485.

Garratt, J., 1994. The atmospheric boundary layer. Cambridge University Press, Cambridge, UK (336 pp.).

Harris, A., Rowland, S., 2009. Effusion rate controls on lava flow length and the role of heat loss: a review. Studies in Volcanology The Legacy of George Walker, 2.

Harris, A., Stevenson, D., 1997a. Thermal observation of degassing open conduits and fumaroles at Stromboli and Vulcano using remotely sensed data. J. Volcanol. Geotherm. Res. 76, 175-198.

Harris, A., Stevenson, D., 1997b. Magma budgets and steady-state activity of Vulcano and Stromboli volcanoes. Geophys. Res. Lett. 24, 1043-1046.

Harris, A., Lodato, L., Dehn, J., Spampinato, L., 2009. Thermal characterization of the Vulcano fumarole field. Bull. Volcanol. 71 (4), 441-458.

Högström, U., 1988. Non-dimensional wind and temperature profiles in the atmospheric surface layer: a re-evaluation. Bound.-Layer Meteorol. 42 (1), 55-78.

Kneizys, F., Shettle, E., Gallery, W., Chetwynd, J., Abreu, L., Selby, W., Clough, S., Fenn, R., 1983. Atmospheric transmittance/radiance: computer code LOWTRAN 6. Technical Report. Air Force Geophysics Laboratory (197 pp.).

Komorowski, J., Boudon, G., Semet, M., Beauducel, F., Anténor-Habazac, V., Bazin, S., Hammouya, G., Cheminée, J., 2005. Guadeloupe. Volcanic Atlas of the Lesser Antilles, University of the West Indies, pp. 63-100.

Kwor, E., Matte, S., 2001. Emissivity measurements for Nextel Velvet Coating 811-21 between $-36{ }^{\circ} \mathrm{C}$ and $82^{\circ} \mathrm{C}$. High Temp. High Pressures 33, 551-556.

Le Guern, F., Bernard, A., Chevrier, R., 1980. Soufrière of Guadeloupe 1976-1977 eruption: mass and energy transfer and volcanic health hazards. Bull. Volcanol. 43 (3), 577-593.

Lettau, H., 1969. Note on aerodynamic roughness-parameter estimation on the basis of roughness-element description Research and Development Technical Report, 8, pp. 828-832.

Lowell, R., 1991. Modeling continental and submarine hydrothermal systems. Rev. Geophys. 29 (3), 457-476.

Luna, E., Córdova, A., Medina, A., Higuera, F., 2002. Convection in a finite tilted fracture in a rock. Phys. Lett. A 300 (4-5), 449-455. 
Macdonald, R., Griffiths, R., Hall, D., 1998. An improved method for the estimation of surface roughness of obstacle arrays. Atmos. Environ. 32 (11), 1857-1864.

Mascart, P., Noilhan, J., Giordani, H., 1995. A modified parameterization of flux-profile relationships in the surface layer using different roughness length values for heat and momentum. Bound.-Layer Meteorol. 72 (4), 331-344.

Matsushima, N., Kazahaya, K., Saito, G., Shinohara, H., 2003. Mass and heat flux of volcanic gas discharging from the summit crater of Iwodake volcano, Satsuma-Iwojima, Japan, during 1996-1999. J. Volcanol. Geotherm. Res. 126, 285.

NASA, 1976. US Standard Atmosphere. GPO, Washington DC (241 pp.)

Neri, A., 1998. A local heat transfer analysis of lava cooling in the atmosphere: application to thermal diffusion-dominated lava flows. J. Volcanol. Geotherm. Res. 81, 215-243.

Nicollin, F., Gibert, D., Beauducel, F., Boudon, G., Komorowski, J., 2006. Electrical tomography of La Soufrière of Guadeloupe Volcano: field experiments, 1D inversion and qualitative interpretation. Earth Planet. Sci. Lett. 244 (3), 709-724.

Noguchi, K., Kamiya, H., 1963. Prediction of volcanic eruption by measuring the chemical composition and amounts of gases. Bull. Volcanol. 26 (1), 367-378.

Oppenheimer, C., 1993. Infrared surveillance of crater lakes using satellite data. J. Volcanol. Geotherm. Res. 55 (1-2), 117-128.

OVSG-IPGP, 2012. Bilan Mensuel de l'Activité Volcanique de la Soufrière et de la Sismicité régionale, Observatoire Volcanologique et Sismologique de la Guadeloupe (1999-2012). Technical report. Observatoire Volcanologique et Sismologique de la Guadeloupe, Institut de Physique du Globe de Paris, IPGP-CNRS-INSU-Conseil Général de Guadeloupe (Website, http://www.ipgp.jussieu.fr/pages/0303040901.php).

Owen, P., Thomson, W., 1963. Heat transfer across rough surfaces. J. Fluid Mech. 15 (3), 321-334.

Peltier, A., Finizola, A., Douillet, G., Brothelande, E., Garaebiti, E., 2012. Structure of an active volcano associated with a resurgent block inferred from thermal mapping: the Yasur-Yenkahe complex (Vanuatu). J. Volcanol. Geotherm. Res. 243-244, 59-68.

Pieri, D., Abrams, M., 2005. ASTER observations of thermal anomalies preceding the April 2003 eruption of Chikurachki volcano, Kurile Islands, Russia. Remote Sens. Environ. 99 (1), 84-94.
Pozzi, J., Mouël, J., Rossignol, J., Zlotnicki, J., 1979. Magnetic observations made on La Soufrière Volcano (Guadeloupe) during the 1976-1977 crisis. J. Volcanol. Geotherm. Res. 5 (3), 217-237.

Pruppacher, H., Klett, J., Wang, P., 1998. Microphysics of clouds and precipitation. Taylor \& Francis (954 pp.).

Rabinowicz, M., Sempéré, J.-C., Genthon, P., 1999. Thermal convection in a vertica permeable slot: implications for hydrothermal circulation along mid-ocean ridges. J. Geophys. Res. 104 (B12), 29275-29292.

Rodriguez, M., 1998. An overview on the seismicity of Cuba. J. Seismol. 2 (4), 323-335.

Schlichting, H., 1968. Boundary layer theory. McGraw-Hill, New-York (826 pp.).

Sekioka, M., Yuhara, K., 1974. Heat-flux estimation in geothermal areas based on heat balance of ground surface. J. Geophys. Res. 79 (14), 2053-2058.

Sheridan, M., 1980. Pyroclastic block flow from the September, 1976, eruption of La Soufrière volcano, Guadeloupe. Bull. Volcanol. 43 (2), 397-402.

Smith, W., 1942. The thermal conductivity of dry soil. Soil Sci. 53 (6), 435-460.

Spampinato, L., Calvari, S., Oppenheimer, C., Boschi, E., 2011. Volcano surveillance using infrared cameras. Earth Sci. Rev. 106 (1-2), 63-91.

Su, Z., Schmugge, T., Kustas, W., Massman, W., 2001. An evaluation of two models for estimation of the roughness height for heat transfer between the land surface and the atmosphere. J. Appl. Meteorol. 40 (11), 1933-1951.

Taylor, S., 1979. Measured emissivity of soils in the southeast United States. Remote Sens. Environ. 8 (4), 359-364.

Verhoef, A., De Bruin, H., Van den Hurk, B., 1997. Some practical notes on the parameter kB-1 for sparse vegetation. J. Appl. Meteorol. 36 (5), 560-572.

Wright, R., Blake, S., Harris, A., Rothery, D., 2001. A simple explanation for the space-based calculation of lava eruption rates. Earth Planet. Sci. Lett. 192 (2), 223-233.

Yuhara, K., Sekioka, M., Ehara, S., 1978. Infrared measurement on Satsuma-Iwojima island, Kagoshima, Japan, by helicopter-borne thermocamera. Meteorog. Atmos. Phys. 27 (2), 171-181.

Yuhara, K., Ehara, S., Tagomori, K., 1981. Estimation of heat discharge rates using infrared measurements by a helicopter-borne thermocamera over the geothermal areas of Unzen Volcano, Japan. J. Volcanol. Geotherm. Res. 9 (1), 99-109. 